\title{
Electrochemical Rapid Determination of Oxygen Content of Liquid Steel in Commercial LD Converter*
}

\author{
By Mutsumi IHIDA** and Yoshihiko KAWAI**
}

\begin{abstract}
Synopsis
In order to apply EMF method to the rapid determination of oxygen content of molten steel in a commercial LD converter, primary studies had been carried out first by using a furnace with a graphite heating element. Then, a device to use in a practical LD converter was developed successfully. The device is like a temperature measuring device of molten steel, and composed of a holder and a consumable part covered with a paper sleeve. Air is used as the reference and a piece of small rod of $\mathrm{ZrO}_{2}$ stabilized by $\mathrm{CaO}$ is fused at the end of quartz tube as an electrolyte sensor in the consumable part. In a commercial $80 t$ LD converter, the influence of slag and temperature difference between the inside and the outside of the electrolyte were also clarified.

After correcting the thermal EMF caused by the temperature difference, relation between EMF and the analysed oxygen values is nearly in agreement with the theoretical value obtained in $\mathrm{Fe}-\mathrm{C}-\mathrm{O}$ melts in the small-scale furnace.

Reproducibility of this method is fairly good and within $5 \%$ in the coefficient of variation.
\end{abstract}

\section{Introduction}

It should be of much value in steel making process to measure rapidly the oxygen content of molten steel in a LD converter, an electric furnace, and a ladle, for the control of deoxidation and rimming action.

To date, an innert gas carrier method or an activation analysis has been developed for the rapid determination of oxygen and they show much advantage in commercial use. However, in these methods, extra time of 2 to $4 \mathrm{~min}$ is required for sampling molten steel from the vessels and the preparation of samples.

On the other hand, an EMF method with a solid electrolyte needs not such extra time. Therefore, it seems to be the most suitable and attractive method for the practical application to the steel making process.

Since a pioneering study by Kiukkola \& Wagner ${ }^{1)}$ many vigorous studies have been carried out in order to use solid electrolytes for the measurement of oxygen potential in various phases at elevated temperature. ${ }^{2-10)}$ Nowadays, also in the field of molten steel, some commercial measuring devices are in the market. Nevertheless, this method has not yet been used so widely in the practical steel making processes because of difficult conditions such as high temperature, presence of slag, and other unfavorable environments. For the practical application of this method to steel making processes, primary studies have been carried out by using a furnace ${ }^{11)}$ with a graphite heating element and finally a practical apparatus for a commercial LD converter is developed successfully.

In this report, details of the development of the ap- paratus and some problems on measurement are described.

\section{Experiment}

The principle of this method is already well known, and expressed generally as follows,

$$
E=-\frac{R T}{n F} \ln \frac{a_{\mathrm{O}}}{P_{\mathrm{O}_{2}}}-\frac{\Delta G^{\circ}}{n F}
$$

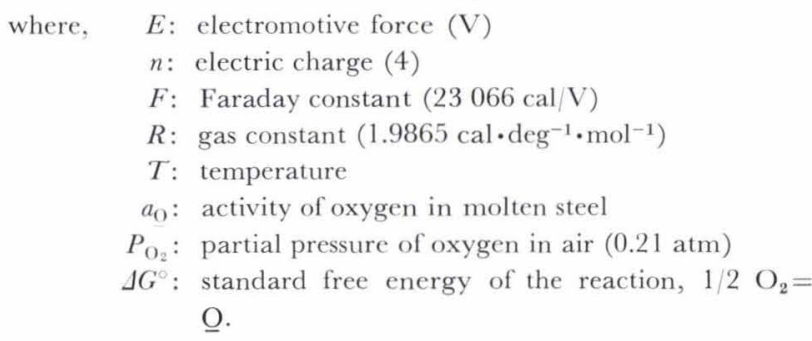

Content of oxygen (dissolved oxygen) in molten steel can be determined by measuring $E$ (electromotive force) according to Eq. (1).

\section{Experimental Apparatus and Its Procedure}

A stabilized zirconia tube with a reference electrode in it was dipped in molten iron heated by the Tamman furnace with a graphite heating element. Experimental procedures are as follows: electrolytic iron (1 kg) was melted in an alumina or a magnesia crucible in the Tamman furnace. After melting iron, a solid electrolyte tube $(12 \phi \times 8 \phi \times 300 \mathrm{~mm})$ on the market was immersed from the upper side of the furnace into molten steel gradually, in order to minimize thermal shock. Inside of this electrolyte tube, $\mathrm{PR}-13$ thermocouple $(0.5 \phi \mathrm{mm})$ was inserted previously and its hot junction was contacted with the bottom of the tube. An alumina tube $(4 \phi \times 2 \phi \times 400 \mathrm{~mm})$ was served to the insulation of the thermocouple and the reference air was flown through it. Air was supplied by an air pump, from the top to the bottom of the tube through a flow meter. After immersing $0.5 \phi \mathrm{mm}$ molybdenum lead into molten steel, EMF between this molybdenum electrode and platinum or rhodium lead of the thermocouple was measured with a Honeywell MV meter. In order to compare measured EMF with the oxygen content of molten iron, samples were taken by $5 \mathrm{~mm}$ ID quartz tube and used for oxygen analysis by vacuum fusion or argon carrier method. The oxygen content in molten steel was controlled by adding carbon or iron ferric oxide $\left(\mathrm{Fe}_{2} \mathrm{O}_{3}\right)$ into molten iron.

\footnotetext{
* Presented at the 77th ISIJ Meeting, March, 1969, in Tokyo and at the 80th ISIJ Meeting, October, 1970, in Amagasaki. Manuscript received October 4, 1971.

** Technical Research Center, Nippon Kokan K. K., Minamiwatarida-cho, Kawasaki-ku, Kawasaki 210.
} 


\section{Problems on EMF Measurement}

Following problems would have to be taken into account of measuring EMF.

\section{Selection of Electrolyte}

$\mathrm{ZrO}_{2} \cdot \mathrm{CaO},{ }^{7)} \mathrm{ThO}_{2} \cdot \mathrm{Y}_{2} \mathrm{O}_{3},{ }^{12)} \mathrm{MgO},{ }^{2)}$ and $\mathrm{Al}_{2} \mathrm{O}_{3}{ }^{13)}$ have been used as electrolytes in many studies of oxygen concentration cell and their characteristics were reported. Other electrolytes can be also produced for laboratory use. But in the case of a large amount of use at steel works, it is convenient to use electrolyte on the market. Therefore, $\mathrm{ZrO}_{2}$ stabilized by $\mathrm{CaO}$ on the market was employed for the electrolyte.

\section{Heat Shock Resistance of the Electrolyte}

$\mathrm{ZrO}_{2}$ stabilized by $\mathrm{CaO}$ is chemically very strong at elevated temperature and it can be used continuously 40 to $50 \mathrm{~min}$ in molten steel at $1600^{\circ} \mathrm{C}$. But it is very weak against heat shock. For example, a $\mathrm{ZrO}_{2}$ stabilized by $\mathrm{CaO}$ tube $(12 \phi \times 8 \phi \times 300 \mathrm{~mm})$ is destroyed immediately when it is immersed into molten steel without preheating. Countermeasures against this heat shock will be discussed in later.

3. Flow Rate of Air and Temperature Difference between the Inside and the Outside of the Electrolyte

Strictly speaking, measured EMF changes with the flow rate of air. EMF rises up with the increase of flow rate because of cooling effect and droppes suddenly at zero flow rate of air. However with flow rates between 100 and $600 \mathrm{ml} / \mathrm{min}$, the EMF shows nearly same values. Causes of these phenomenon will be estimated as follows.

(1) Influence of gas diffusion caused by permeability of solid electrolytes.

(2) Temperature difference between the inside and the outside of the electrolyte.

Oxygen permeation through the electrolyte seems primarily responsible for the zero EMF at zero flow rate. Also, temperature difference between the inside and the outside of the electrolyte will influence strongly on EMF measurement as indicated by Goto ${ }^{14}$ et al. Because air was blown into solid electrolyte tube with cooling effect of air, the inside temperature of the electrolyte will be lower than the outside one of the tube (i.e. molten steel side). This temperature difference was measured and the difference in temperature was increased with the flow rate of air. Accordingly, the EMF of the cell does not obey isothermal cell EMF calculated thermodynamically from Eq. (1), but will be explained by EMF of thermo-galvanic cell which has temperature difference between both sides of the electrolyte. This EMF of thermogalvanic cell will be discussed later in details. The flow rate of air of $200 \mathrm{ml} / \mathrm{min}$ is employed so as to neglect the cooling effect of air in the experiment by Tammann furnace.

\section{Thermo-emf between Different Metallic Lead Wire}

In the experiment, metallic lead wires are composed of platinum or rhodium at reference side and molibdenum at molten steel side. Consequently, thermo-emf between these different metallic lead wires should be substracted from the total EMF. These thermo-emf have been measured in advance.
5. Correction According to Oxygen Activity and Transference Number of the Electrolyte

Equation (1) tells us that this method gives the chemical activity of dissolved oxygen. Therefore, in next two cases oxygen content values obtained from measured EMF are different from those analysed by the usual method.

(1) In case where there are co-existed elements which influence oxygen activity in molten steel.

(2) In case where there are non-metallic inclusions (oxide).

On commercial use, it is very important problem how to calibrate these measured EMF. The transference number of oxygen ions in the solid electrolyte is desirable to be unity under measuring condition in application of this method to molten steel. However, it would often become lower than unity ${ }^{15}$ ) because of high temperature and low oxygen potential especially below 200 ppm of oxygen. These problems should be solved strictly when this method is applied to measure absolute values of oxygen activity in thermodynamical studies. However such problems are not so important in the case of commercial application, as long as a good calibration curve is obtained.

\section{Experimental Results}

Figure 1 shows relation between EMF measured in a Tammann furnace and analysed oxygen values. Molten steel were both $\mathrm{Fe}-\mathrm{C}-\mathrm{O}(<0.6 \% \mathrm{C})$ and $\mathrm{Fe}-$ $\mathrm{C}-\mathrm{Mn}-\mathrm{O}$ system $(<0.6 \% \mathrm{C},<0.3 \% \mathrm{Mn})$ and its temperature were $1600^{\circ} \pm 20^{\circ} \mathrm{C}, 1500^{\circ} \pm 20^{\circ} \mathrm{C}$ respectively. As shown in Fig. 1, relation between EMF and logarithm oxygen values is expressed by a fairly good linear relation in either system. Differences in the EMF between the two systems at the different temperatures could not be seen because of errors included in the experiment and analysis. Then it is concluded that dissolved oxygen in molten steel in the range of 60 to $1500 \mathrm{ppm}$ can be obtained from EMF measurement according to the calibration curve in Fig. 1. The precision of this measurement is very good, and its coefficient of variation is within a few percent. Moreover, gradient of calibration curve in Fig. 1 is a little less

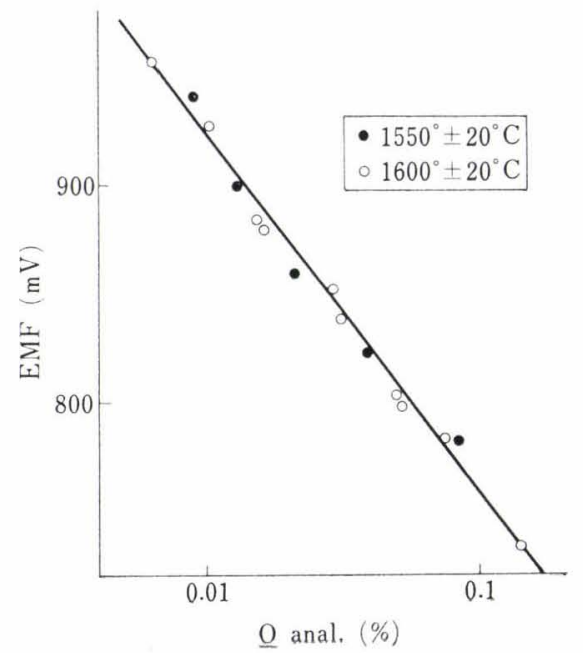

Fig. 1. Relation between measured EMF and analysed oxygen content 
than that of theoretical curve calculated from Eq. (1) probably because of an electronic conductivity, but both are nearly same.

From the results of the primary experiment in a Tammann furnace, it can be concluded that the application of this method to commercial use at steel works is fairly promising.

\section{Example of Measurement during Silicon Deoxidation}

One attempt was made to trace the changing pattern of oxygen activity during silicon deoxidation. In the Tammann furnace, after $1 \mathrm{~kg}$ of electrolytic iron was melted, metal bath was stirred well by blowing argon gas as soon as metallic silicon (about $0.3 \%$ of melts) was added to the bath. During these procedures, EMF was measured at intervals and at the same time samples were taken by $5 \phi \mathrm{mm}$ quartz tube. Oxygen of the samples were analysed by argon carrier fusion method and acid soluble silicon by dilute sulfuric acid photometric method. On the other hand, dissolved oxygen was read from measured EMF with the aid of calibration curve in Fig. 1. The dissolved oxygen values obtained from EMF measurement agree fairly well with equilibrium oxygen values which are obtained thermodynamically from analytical values of soluble silicon. Further, an abrupt decreasing tendency of dissolved oxygen within a minute after silicon addition also agrees with the results of isotopic study of silicon deoxidation by Miyashita. ${ }^{16)}$

Accordingly it is expected that this method can also be applied to systems in which both deoxidizing element and deoxidation products exist.

\section{Device for Practical Use}

According to the above described investigation and conclusion, a device was developed for oxygen measurement in molten steel at practical steel work. For oxygen measurement, the similar procedure was employed as temperature measurement at a LD converter.

\section{Necessary Condition as a Device for Practical Use}

Following conditions are considered to have to be satisfied by a device for practical use:

(1) A good thermal resistance at elevated temperature

(2) A good heat shock resistance

(3) A good mechanical strength

(4) Easy treatment

(5) Good accuracy and precision

(6) Low cost

Either condition (1) or (2) is fundamental one to be solved at first by the electrolyte sensor.

\section{Development of a Solid Electrolyte Sensor}

In the early stage of the trial manufacture of a device, heat shock resistance of an electrolyte sensor was improved and at last it was found that a sensor composed of quartz tube and small block of an electrolyte fused at the end of the said tube, had very strong heat shock resistance and could be used without pre-heating. After a lot of investigation about shape and size of the electrolyte as well as structure of electrode, a sensor which was composed of a piece of small rod of $\mathrm{ZrO}_{2}$ stabilized by $\mathrm{CaO}$ electrolyte $(1 \phi-2 \phi \mathrm{OD} \times 8 \mathrm{mmL})$ fused at the end of quartz tube was employed from the reasons that this type of electrolyte was the easiest one to make and a sensor was made most easily by using this electrolyte and had the most high percentage of good measurements. The electrolyte rod was grooved around at the top of it, easily to roll metallic lead wire. This sensor was first used in the Tammann furnace, and the EMF obtained by this sensor showed good agreement with those obtained by an electrolyte tube. Further, this sensor was far cheaper than the electrolyte tube of $\mathrm{ZrO}_{2}$ stabilized by $\mathrm{CaO}$ because of a very small piece. The sensor was connected to the top of steel holder which was like a temperature measuring device in molten steel.

\section{Trial Manufacture of a Measuring Device}

The above mentioned sensor was at first settled at the top of a temperature measuring device called "permanent type" whose surface was protected by graphite sleeve. When this device was used for measurement of oxygen in molten steel in an open hearth or a converter, the relation between measured EMF and analysed oxygen was fairly well and percentage of success was very high. However, this device had many deffects such that it was very heavy and it took much time to exchange and maintain the sensor. As the next step, we tried to use a type of temperature measuring device on which surface were covered with paper sleeve and which had been used up to date for temperature measurement in a LD converter. Although there were so various difficulties until the completion of the device, after repeating investigation and improvement the authors could develop a measuring

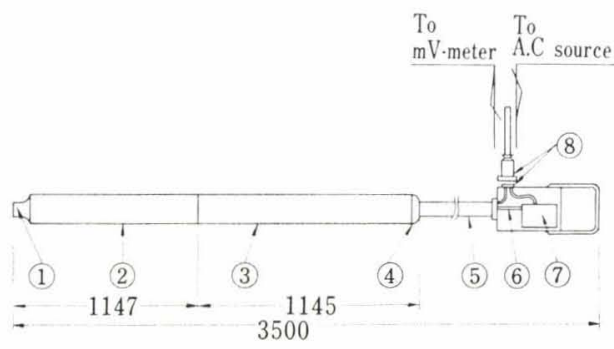

$\begin{array}{lllll}\text { (1) Steel cap } & \text { (4) } & \text { Stopper } & \text { (7) } & \text { Air pump } \\ \text { (2) Paper sleeve } & \text { (5) } & \text { Steel pipe } & \text { (8) } & \text { Metallic } \\ \text { (3) Paper sleeve } & \text { (6) } & \text { Air blowing tube } & & \text { connecter }\end{array}$

Fig. 2. Whole diagram of a measuring device (Unit, $\mathrm{mm}$ )
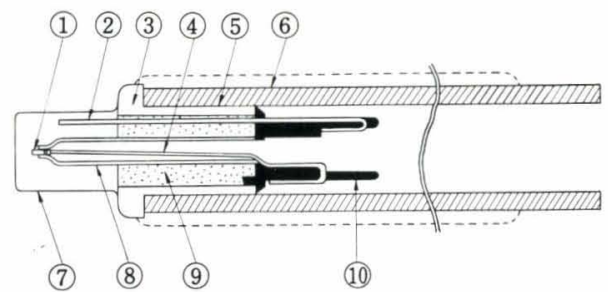
(1) $\mathrm{ZrO}_{2} \cdot \mathrm{CaO}$ tip
(2) Mo lead
(5) Paper sleeve
(9) $\mathrm{Al}_{2} \mathrm{O}_{3}$ cement
Ceramic brim
6) Ceramic coating
(7) Steel cap
(10) Plastic

4) $\mathrm{Pt}$ lead (8) $\mathrm{SiO}_{2}$ tube

Fig. 3. Schematic diagram of a consumable part of a measuring device 


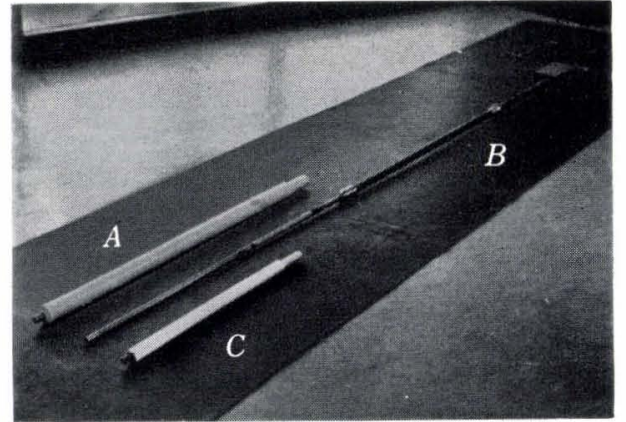

A : consumable part used in a LD converter B: holder

C: consumable part used in a ladle or a mold Photo. 1. Measuring device
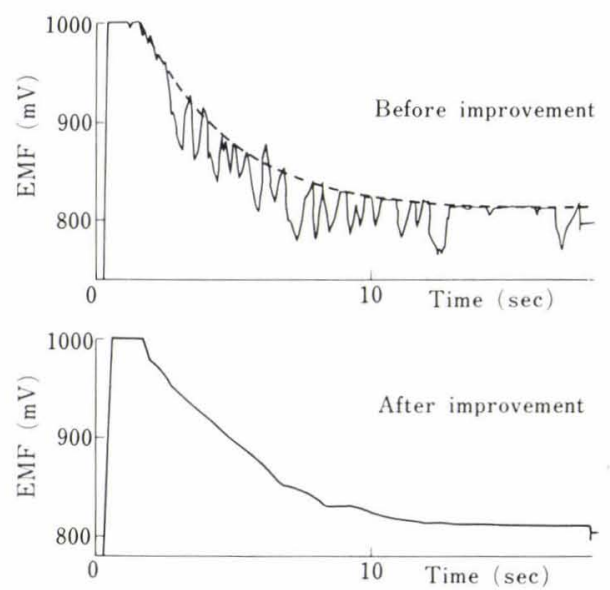

Fig. 4. Typical chart profiles before and after improvement

device which endured commercial use. Figure 2 shows the whole diagram of this device and Fig. 3, the structure of consumable part of it. In Fig. 2, an air pump, (7) is mounted in a box set up at the end of steel holder and air is flashed out (by this pump) from the top of this holder through an air blowing tube, (6). Consumable part shown in Fig. 3 is set at the top of the holder. It is composed of the sensor, molybdenum rod, (2) for completion of electric lead to molten steel and ceramic brim, (3) covered with paper sleeve, (5). In order to connect the lead wire of consumable part to a holder side connecter, a plastic connecter, (10) is connected with said brim, (3). The quartz tube of the sensor is opened at connecter side so that the head of $\mathrm{ZrO}_{2}$ stabilized by $\mathrm{CaO}$ may be refreshed by air flashed out from the holder when consumable part is connected with the holder. Both holder and consumable part are shown in Photo. 1. Surface of $\mathrm{A}$ is paper alone but $\mathrm{C}$ is covered with ceramics in order to prevent one from the splash of molten steel. Holder B is capable of using with each consumable part. A chart in which EMF reaches to stable state after $10 \mathrm{sec}$ from immersion of this holder and a consumable part into molten steel is shown in Fig. 4. Reading-out of stable EMF after about 12 to $13 \mathrm{sec}$ from immersion of the device makes it possible to determine rapidly oxygen content of molten steel.
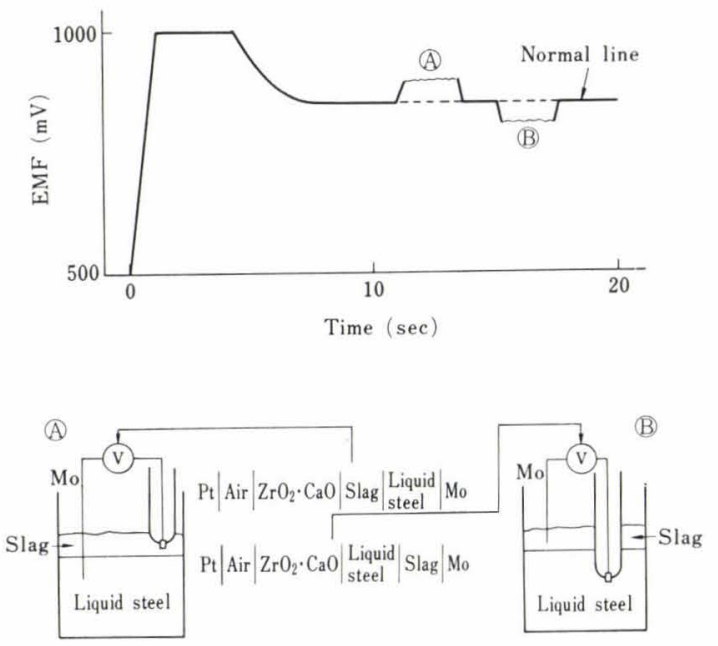

Fig. 5. Influence of slag observed on EMF chart profile

\section{Some Problems in the Manufacture of a Measuring Device}

There were many problems to be solved in manufacturing a practical measuring device. Some difficulties will be discussed below.

\section{Protection of a Piece of Molybdenum Rod as a Counter Electrode}

Typical chart profiles before and after improvement of counter molybdenum electrode are compared together in Fig. 4. Unstable chart profile of the EMF before improvement is considered to be caused by mainly gas evolution by thermal decomposition of the paper sleeve which might have intermitted electrical connection between molybdenum counter electrode and molten steel. After improvement of using a piece of longer molybdenum rod and covering outside of it with quartz tube, stable chart profile was obtained as shown in Fig. 4.

\section{Interference of Slag}

On the final stage of steelmaking, LD converter is laid down for sampling of molten steel or measuring of the temperature of steel bath. But considerable amounts of slag are still present on molten steel. During measurement of EMF in LD converter, sometimes quick drop or unstable state of EMF have occurred. Observing electrodes after measurement carefully, these phenomena seem to be caused by the contact of slag with an electrolyte sensor or a counter electrode. Then in order to make this influence of slag clear, an experiment was carried out about slag which was floated on molten steel melted in the laboratory $50 \mathrm{~kg}$ high frequency induction furnace. The results are shown in Fig. 5 and it is found that if an electrolyte sensor is immersed into slag (State (A)), EMF rises up nearly $50 \mathrm{mV}$ over a normal level, on the other hand, if counter molybdenum electrode is immersed into slag (state (B) in Fig. 5) EMF falls down 20 to $40 \mathrm{mV}$ under a normal level and these reactions are reversible. In short, if either an electrolyte sensor or an counter molybdenum electrode is immersed into slag, it causes bias or variance of EMF.

In the practical measurement of EMF in a LD con- 


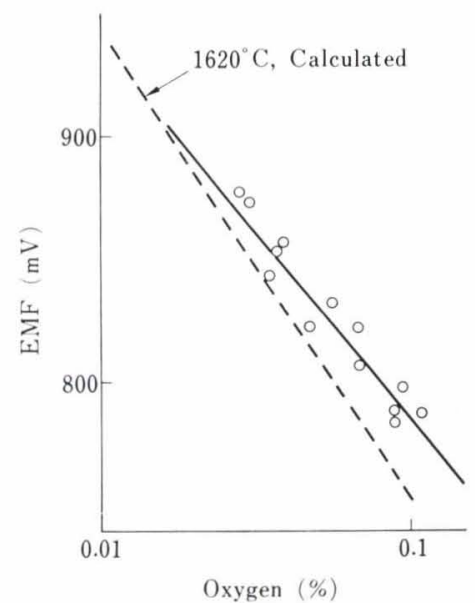

Fig. 6. Relation between measured EMF and analysed oxygen content

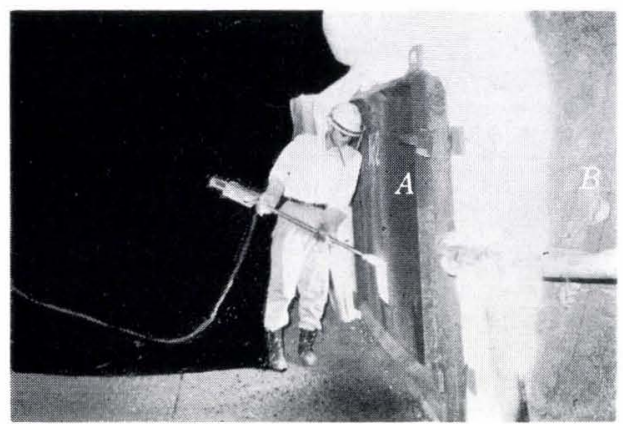

A : measuring device B: furnace

Photo. 2. Practical measurement at the end point of a commercial LD converter $(80 \mathrm{t})$

verter, the thickness of slag layer or the level of molten steel is variable with the capacity and the refractory lining conditions of a furnace or the amounts of foamed slag. Therefore, it is important to control carefully the length of the holder or inserting angle into steel bath in order to immerse both electrodes steadily into molten steel through the slag layer. It is natural that the sensor is covered with steel cap as shown in Fig. 3.

5. The Influence of Difference in Temperature between the Inside and the Outside of an Electrolyte and Its Correction

At the end point of steelmaking of a LD converter $(80 \mathrm{t})$, EMF was measured and compared with analytical oxygen values of samples which were almost simultaneously taken from the converter by direct sampling equipment. The obtained results are shown in Fig. 6 and the photograph of the practical measurement is shown in Photo. 2. It is made clear that there is a significant correlation between EMF and analytical oxygen values, however, measured EMF is generally higher than theoretically calculated EMF at $1600^{\circ} \mathrm{C}$, and the slope of correlation line of measured EMF vs. analysed oxygen values is less than that of theoretically calculated line. The followings are considered as the reasons of these deviation:

(1) Influence of difference in temperature between the inside and the outside of the electrolyte.
(2) Influence of oxide inclusions contained in steel samples.

A less slope of the line is considered to be caused by the decrease in transference number of oxygen ion in the electrolyte especially in low oxygen range.

Investigation was carried out to solve the first problem. In a practical measurement device, the flow rate of air is kept at higher level $(800 \mathrm{ml} / \mathrm{min})$ in order to get stable profile on a chart than that in laboratory Tammann furnace experiment $(200 \mathrm{ml} / \mathrm{min})$ in which the temperature difference is negligibly small. Therefore, the temperature of the inside of the electrolyte was naturally expected to be lower than that of the outside (liquid steel side) and the temperature difference would not be negligible. The inside temperature of the electrolyte was measured by inserting $\mathrm{PR}-13$ ( $\mathrm{Pt}-\mathrm{Pt}$ Rh13\%) thermocouple and compared with the temperature of molten steel which was measured by an usual immersion thermo-couple (Table 1). From Table 1 the temperature difference by $17^{\circ} \mathrm{C}$ in average was obtained in the molten steel temperature range from $1605^{\circ}$ to $1645^{\circ} \mathrm{C}$. EMF caused by this temperature difference was calculated according to the thermogalvanic cell theory. Its cell construction is shown as follows:

$$
\begin{aligned}
& \mathrm{O}_{2} \text { in air } / \mathrm{O}^{--} \text {electrolyte } / \underline{\mathrm{O}} \text { in liquid iron... } \\
& \text { Phase } A
\end{aligned}
$$

where phase $A$ and phase $B$ express the inside and the outside (molten steel side) of electrolyte respectively and reaction at each phase is shown as follows.

$$
\begin{array}{ll}
\text { Phase } A: & \mathrm{O}_{2}+4 e=2 \mathrm{O}^{--} \\
\text {Phase } B: & 2 \mathrm{O}^{--}=2 \underline{\mathrm{O}}+4 e
\end{array}
$$

If the activity of $\mathrm{O}^{--}$in an electrolyte is equal at the two interfaces, the additional EMF, $(\Delta E)$, caused by the difference in temperature can be represented as follows :

$$
\begin{aligned}
\Delta E= & \frac{1}{n F} \int_{T_{A}}^{T_{B}} S^{\mathrm{o}} d T+\frac{R}{n F}\left(T_{A}-T_{B}\right) \ln P_{\mathrm{O}_{2}} \\
& +\alpha\left(\mathcal{T}_{A}-T_{B}\right) \ldots \ldots \ldots \ldots \ldots \ldots \ldots \ldots \ldots \ldots \ldots \ldots \ldots \ldots \ldots \ldots \ldots \ldots \ldots
\end{aligned}
$$

$T_{A}, T_{B}:$ temperature of phase $A$ and $B$

$\alpha$ : seebeck coefficient of $\mathrm{Pt}-\mathrm{ZrO}_{2}$ stabilized by

\begin{tabular}{|c|c|c|}
\hline $\begin{array}{c}\text { Steel bath } \\
\text { temperature } \\
T_{B}\left({ }^{\circ} \mathrm{C}\right)\end{array}$ & $\begin{array}{c}\text { Temperature of air } \\
\text { blown side of electrolyte } \\
T_{A}\left({ }^{\circ} \mathrm{C}\right)\end{array}$ & $\begin{array}{c}\text { Temperature } \\
\text { difference } \\
\Delta T\left({ }^{\circ} \mathrm{C}\right)\end{array}$ \\
\hline 1640 & 1615 & 25 \\
\hline 1610 & 1600 & 10 \\
\hline 1645 & 1630 & 15 \\
\hline 1630 & 1610 & 20 \\
\hline \multirow[t]{3}{*}{1605} & 1590 & 15 \\
\hline & $\bar{x}$ & 17 \\
\hline & $a$ & 6 \\
\hline
\end{tabular}
$\left.\mathrm{CaO}, \quad\left(0.095 \mathrm{mV} /{ }^{\circ} \mathrm{C}\right)^{\mathbf{1 4}}\right)$

$S^{\circ}$ : $\quad$ standard entropy of one mole of oxygen gas. From thermodynamic data,

Table 1. Results of temperature measurement of both sides of an electrolyte 


$$
\begin{aligned}
S^{0}=8.32 \ln \mathcal{T} & +3.95 \times 10^{-4} \mathcal{T}+1.89 \times 10^{5} \mathcal{T}^{-2} \\
& +0.24
\end{aligned}
$$

for 1 mole of oxygen gas and $P_{\mathrm{O}_{2}}=0.21 \mathrm{~atm}$. By substituting these values and arbitrary values of $T_{A}$ and $T_{B}$ in the range of bath temperature $\left(1500^{\circ}\right.$ to $1700^{\circ} \mathrm{C}$ ) into Eq. (5), it is shown that $\Delta E$ has closely linear relation with $\Delta T\left(=T_{B}-T_{A}\right)$ and can be approximately represented by simple equation of $\Delta E(\mathrm{mV})=0.8 \Delta \mathcal{T}$ $\left({ }^{\circ} \mathrm{C}\right)$ being independent of bath temperature in the range from $1500^{\circ}$ to $1700^{\circ} \mathrm{C}$. As shown already in Table 1, the average temperature difference of the inside and the outside of the electrolyte is about $17^{\circ} \mathrm{C}$ during measurement in steel bath, additional thermal EMF caused by this temperature difference corresponds to about $14 \mathrm{mV}$. After correcting this value, the comparison of EMF measured in a LD converter with those obtained in a Tammann furnace experiment shows favourable agreement (Fig. 7).

The EMF in the Tammann furnace experiment is obtained in molten electrolytic iron in addition of only carbon. In that case, the whole oxygen values in molten iron i.e. analytical oxygen values are considered to represent soluble oxygen. Therefore, the agreement of both results of EMF vs. analytical oxygen values means the most oxygen at the end point of a LD converter are also soluble oxygen and then calibration curve obtained in the Tammann furnace is generally available to use in a practical LD converter, after correcting the thermal EMF caused by the temperature difference. Strictly speaking, as shown in Fig. 7, small difference seems to be present between the results in the Tammann furnace and those in the LD converter and the later indicates a little higher oxygen. The difference may be caused by the presence of oxide in molten steel in the LD converter, but the difference is within the range of error and seems too difficult to discuss more detail.

\section{Reproducibility of This Method}

Coefficients of variation of this method which are calculated by considering the analytical oxygen as standard value are 6 and $13 \%$ in the Tammann furnace and the LD converter respectively. However, oxygen values analysed by fusion method contain con-

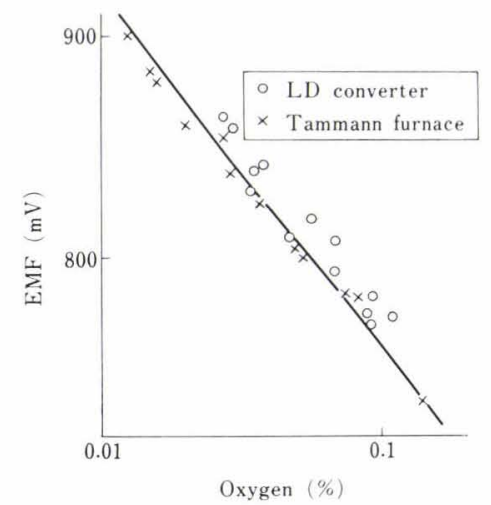

Fig. 7. Comparison of measuring results at LD converter with those at Tammann furnace after correcting additional EMF siderable amounts of error especially in sampling from the furnace, therefore the true reproducibility of this method can not be estimated by the comparison of only analysed oxygen values. In order to know the reproducibility of this method in the furnace, EMF values were measured by immersing two measuring devices into molten steel in the furnace simultaneously. Favourable results were obtained as shown in Table 2 and they indicated that coefficient of variation of this method was within $5 \%$ in the range of oxygen content from 100 to $500 \mathrm{ppm}$.

As one example of the practical measurement of oxygen, relation between oxygen content and carbon content at the end point of 80 t LD converter is shown in Fig. 8.

\section{Conclusion}

(1) In Tammann furnace experiments, commercial $\mathrm{ZrO}_{2}$ tube stabilized by $\mathrm{CaO}$ was used as an electrolyte and air as reference. A good reproducible relation is obtained between measured EMF and oxygen values analysed by fusion method in $\mathrm{Fe}-\mathrm{C}-\mathrm{O}$ and $\mathrm{Fe}-$ $\mathrm{C}-\mathrm{Mn}-\mathrm{O}$ melts. Then, during deoxidation process by silicon, dissolved oxygen obtained from measured EMF shows good agreement with equilibrated oxygen values which are calculated by analysed metallic sili-

Table 2. Reproducibility of oxygen values obtained from simultaneously measured EMF by two oxygen measuring devices

\begin{tabular}{c|c|c|c}
\hline \multirow{2}{*}{ No. } & \multicolumn{2}{|c|}{ Oxygen measuring device } & $R(\mathrm{ppm})$ \\
\cline { 2 - 3 } & No. 1 (ppm) & No. 2(ppm) & \\
\hline 1 & 320 & 320 & 0 \\
2 & 125 & 140 & 15 \\
3 & 315 & 315 & 0 \\
4 & 300 & 300 & 0 \\
5 & 370 & 370 & 0 \\
6 & 315 & 290 & 25 \\
7 & 235 & 210 & 25 \\
8 & 150 & 135 & 15 \\
9 & 185 & 177 & 22 \\
10 & 140 & 118 & \\
\hline$R=11 \mathrm{ppm}$, & $C V=4.2 \%, \quad \sigma=10 \mathrm{ppm}$ &
\end{tabular}

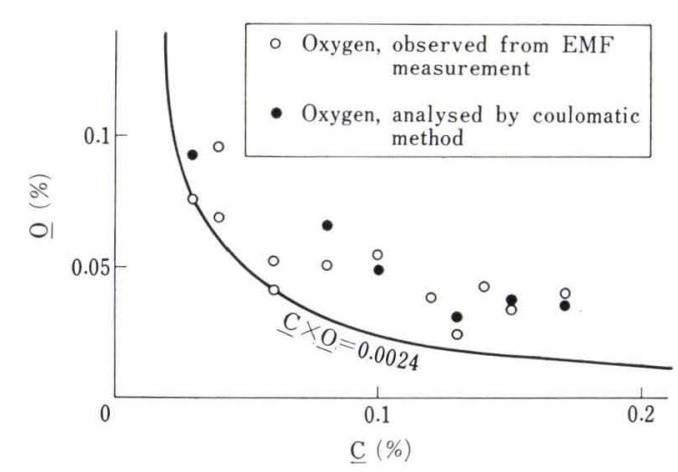

Fig. 8. Plots of oxygen content $(\%)$ in liquid steel vs. carbon content $(\%)$ analysed at the end point of $80 \mathrm{t}$ LD converter 
con, even though they are much lower than analysed total oxygen due to oxide inclusions.

(2) In manufacturing a device, an electrolyte sensor consisted of a piece of small electrolyte rod fused at the end of quartz tube has been developed as heat shock proof one. Then, this sensor settled in ceramic brim is equipped at the end of paper sleeve which can connect with steel holder consumably. In short, this oxygen measurement device is the same type as immersion thermocouple for temperature measurement.

(3) According to clarification that slag influences largely on the measurement in a converter or a ladle, it is important to immerse electrodes surely into molten steel.

(4) As the results of measurement in a LD converter, fairly good relation between EMF and analysed oxygen values is obtained. But it is found that these EMF deviate in higher range than those obtained in $\mathrm{Fe}-\mathrm{C}-\mathrm{O}$ or $\mathrm{Fe}-\mathrm{Mn}-\mathrm{C}-\mathrm{O}$ melts at Tammann furnace experiments since additional EMF is generated by temperature difference between the inside and the outside of electrolyte. According to the equation of thermogalvanic cell with a temperature difference, the measured EMF in a LD converter was corrected and thus, the corrected EMF nearly agreed with those obtained in the Tammann furnace. Thus, it is also found that most of oxygen in a LD converter appears to be free oxygen at the end point of the refining.

(5) Using this device, free oxygen in various furnaces, ladles, and molds can be measured within 20 sec. The precision of this method is 10 to $13 \%$ in the coefficient of variation in reference with the analysed oxygen values (fusion method) of samples taken simultaneously.

Since these values contain errors of sampling and analysis, further investigations about the reproducibility of this method have been made by immersing two devices into molten steel simultaneously and it shows fairly good reproducibility within $5 \%$ in the coefficient of variation.

\section{Acknowledgement}

The authors are indebted to Osaka Oxygen Ind., Ltd. for cooperation in the development and the completion of a consumable oxygen measuring device.

\section{REFERENCES}

1) K. Kiukkola and C. Wagner: J. Electrochem. Soc., 104 (1957), 379.

2) M. Ohtani and K. Sanbongi: Tetsu-to-Hagané, 49 (1963), 22.

3) J. Weissbart and R. Ruka: J. Electrochem. Soc., 109 (1962), 723.

4) K. Goto and G. St. Pierre: Tetsu-to-Hagané, 49 (1963), 1873.

5) Y. Matsushita and K. Goto: Tetsu-to-Hagané, 52 (1966), 827.

6) W. A. Fischer and W. Ackermann: Arch. Eisenhüttemw., 36 (1965), 643 .

7) G. R. Fitterer: J. Metals, 19 Sept. (1967), 92.

8) J. K. Pargeter: J. Metals, 20 Oct. (1968), 27.

9) K. H. Ulrich and K. Borowski: Arch. Eisenhüttenw., 39 (1968), 259.

10) E. T. Turkdogan and R. J. Fruehan: Amer. Iron Steel Inst., Year Book (1968).

11) M. Ihida and Y. Kawai: Tetsu-to-Hagané, 55 (1969), S279.

12) T. Hiraoka, N. Sano, and Y. Matsushita: Tetsu-to-Hagané, 55 (1969), 470.

13) P. Catoul, P. Jyou, and A. Hana: CNRM, June (1967), 57.

14) K. Goto, T. Ito, and M. Someno: Presented at the meeting of 19th committee of the Japan Society for Promotion of Science, Feb. 15, 1969.

15) W. A. Fischer: Arch. Eisenhüttenw., 33 (1967), 422.

16) Y. Miyashita: Tetsu-to-Hagané, 50 (1964), 507. 